\title{
Unintentional Injuries among Under-Five Children in Mid- Western Nepal
}

\author{
Kafle B ${ }^{1}$, Yadav UN ${ }^{2}$, Marhatta SB ${ }^{3}$, Mishra D ${ }^{4}$, Pant ND
}

\section{Abstract}

Introduction: Unintentional injury is the biggest threat to the survival of the under-five children, which impact is immeasurable to families and often entire communities. The objectives of this study were to assess the prevalence of unintentional injuries among under-five children and the factors associated with it. Material and Methods: A facility-based quantitative crosssectional study was conducted from August 2016 to January 2017. Multistage time frame convenient sampling method was applied to collect the data from 259 mothers of under-five children in the selected district of Mid-Western Development region of Nepal. The data was collected from 10 rural health facilities and two from urban setting using a semi-structured questionnaire. An analysis was performed using SPSS ver.15. Results: The prevalence of unintentional injuries was found to be $33.20 \%$ among the under-five children. The present study showed that ecological belt, the age of mothers, education of mothers, education of fathers, the occupation of mothers, the occupation of fathers, family income quintiles, household type, numbers of a sibling, age and gender of children were significant factors associated with unintentional injuries among under-five children. More than $70 \%$ of the respondents were not aware of how to provide first aid care to the children with respect to unintentional injury. Conclusion: This study highlights the burden of unintentional injuries among underfive children in mid-western development region of Nepal. Intervention targeting multifactorial issues in line with all type of fall injuries, burns and injuries with the use of sharp objects might be helpful to tackle the problems.

Key words: Fall injuries, Unintentional injuries, under-five children

\section{Introduction}

W orld Health Organization (WHO) reported lives of more than 2000 families every day around the world experience the loss of a child to an unintentional injury that could have prevented. Unintentional injury is the biggest threat to the survival of the underfive children, which impact is immeasurable to families and often entire community ${ }^{1}$. The leading causes of unintentional injury were
${ }^{1} \mathrm{Mr}$. Bharat Kafle, Department of Public Health, Manmohan Memorial Institute of Health Sciences, Soalteemode, Kathmandu, Nepal, Institute of Medicine, Department of Community Medicine and Public Health, T.U, Nepal, ${ }^{2}$ Mr. Uday Narayan Yadav, Ph.D., Forum for Health Research and Development, Kathmandu, Nepal, Centre for Primary Health Care and Equity, School of Public Health and Community Medicine, UNSW, Australia, ${ }^{3}$ Sujan Babu Marahatta, Ph.D., Department of Public Health, Manmohan Memorial Institute of Health Sciences, Soalteemode, Kathmandu, Nepal, ${ }^{4}$ Ms. Durga Mishra, MPH, Department of Public Health, Manmohan Memorial Institute of Health Sciences, Soalteemode, Kathmandu, Nepal, ${ }^{5}$ Mr. Narayan Dutt Pant, Ph.D., Grande International Hospital, Kathmandu, Nepal.

\section{Address for correspondence}

Mr. Bharat Kafle,

Department of Public Health,

Manmohan Memorial Institute of Health Science,

Kathmandu, Nepal,

Tel No;+977-9857040341

E-mail: bharatkafle29@gmail.com

Acknowledgements: The authors are grateful to the study participants and health facility workers.

\section{Funding: Nil}

\section{Conflict of Interest: None}

Permission from IRB: Yes, from the Institutional Review Board, Manmohan Memorial Institute of Health Sciences.

\section{How to cite}

Kafle B, Yadav UN, Marhatta SB, Mishra D, Pant ND. Unintentional Injuries among UnderFive Children in Mid-Western Nepal. J Nepal Paediatr Soc 2018;38(1):46-52.

doi: http://dx.doi.org/10.3126/jnps.v38i1.18250

This work is licensed under a Creative Commons Attribution 3.0 License. 
falls, burns, other injury intentional strikes, exposure to an unspecified factor and motor vehicle transport ${ }^{2}$.

More than 875,000 children are dying annually in the world due to injury, of which most of them occur in low and middle-income countries (LMIC) ${ }^{3}$. Worldwide each year about 349,000 children aged $<5$ years die due to unintentional injury and $98 \%$ of them died from LMIC.In total $13 \%$ burden of morbidity among $\leq 15$ years of aged children is due to injury and $37 \%$ of deaths in $<20$ years due to unintentional injury. Global burden of disease estimated unintentional injury among $<5$ years children were responsible for 232, 00,187 disability-adjusted life years (DALYs) in 2015 and evaluate 8.9/100,000 children $<5$ death rates. People from deprived and a minority background in poor countries often face more impact of injury ${ }^{4}$. In India figure shows 82,000 children died of which $46.3 \%$ died due to unintentional injury in aged $<5$ children $^{5,6}$. In 2015, an estimated of 1,240 under-five children died from the injury, of them (48.8\%) were of unintentional injury in Nepal. Evidence shows that injuries to children occurs three times more in Nepal than western world ${ }^{4}$. In Nepal non-fatal falls injury being the most common cause of injury in children? Children spending long periods of time in the home and the household environment presents a variety of potential hazards which increases the probability of childhood unintentional injury in the household setting and surrounding environment ${ }^{8}$.

In low-income countries, unintentional injury has remained a major cause of death and disability for millions of children ${ }^{9}$. Injuries proved to have double impact burden of both disease and severe psychological disturbances at the individual level and economic consequences at family level ${ }^{10}$. Every year more than hundred thousand children die from injury and millions of children suffer the consequences of non-fatal injuries ${ }^{1}$.

Fall injury is a common injury among under-five children. It is evidenced that young adults faced higher rates of intentional injuries while children are prone to the unintentional type of injury ${ }^{9}$. Global burden of disease report projected that global death because of injury will increase by $28 \%$ between 2004 and $2030^{11}$.

High-income countries have identified risk and protective factors for individual types of child injury ${ }^{12}$. The literature showed age, sex, race, mother education, socio-economic status, children were not first bornand types of surface are the characteristics of children susceptible to injury or risk factors ${ }^{12,13,14,15,16,17,18}$.

Adequate supervision, engineering measures, environmental measures, law and regulation, educational approaches, community interventions, mass media and pamphlet campaigns, pedestrian education, parent education and research are protective factors for injury 1,19,20,21,22,23. Though this problem is well recognized in the western world in context to Nepal, this problem is not much more focused by researchers except few and lack of effective robust death registration systems data unclear in injury death rates. There is scarce of information on unintentional injuries among under-five children in the mid-western region. This study was adopted to fill the literature gap and findings might help develop interventions for the prevention of unintentional injuries among targeted groups. The objectives of this study were to look at the prevalence and find out the factors associated with unintentional injuries among under-five children of Mid-Western Nepal.

\section{Material and Methods}

This was a facility-based cross-sectional survey was conducted in Bardia, Dailekh and Mugu district of Mid-Western Development Region of Nepal. The study was conducted between August 2016 and January 2017. The study adopted a multi-stage time frame convenient sampling method for selection of study samples that are mothers of under-five children [Figure 1]. The totals of 259 mothers of under-five children were enrolled in the study.

The semi-structured tool prepared after through literature review and was validated by taking expert opinions. The mothers who did not have children below five years were excluded from this study. The data was collected through face to face interview at the health facilities by one of the research team member. All respondents were informed that the data collected would be treated with anonymity and confidentiality. Written informed consent was obtained from the respondents before interviewing them. The research protocol was approved by Institutional Review Committee of Manmohan Memorial Institute of Health Science.

The data were analysed using SPSS version 15 . Frequency and proportion were reported, and the chisquare test was used as a statistical test to check the associations.

\section{Results}

Prevalence of unintentional injuries: Out of the 259 studied samples, the prevalence of self-reported unintentional injuries was the $33.20 \%$ among the underfive children in the selected study sites (Figure 2).

Socio-demographic characteristics of the respondents: In this study socio-demographic variables shows that $45.56 \%$ of mothers were in age group of 21 to 
25 years with a median age of 25 years and interquartile range of mother aged group of (22 and 29). Additionally, this study shows that the median age of marriage of mothers was 17 years. All of the respondent mothers were married, and majorities of the respondent were ascribed as Hindu religion $93.82 \%$, followed by Islam and others $3.9 \%$ and $2.3 \%$ respectively. The major occupations of mothers were a housewife (39.0\%) and others engaged in agriculture, business and daily wages $(35.9 \%, 12.4 \%$, and $5.4 \%)$ respectively. Our study shows a majority of mothers one quarter (25.1\%) were illiterate and followed by higher secondary, primary and secondary education $(22.0 \%, 21.6 \%$, and $16.2 \%)$ respectively. The present study revealed that 3 out of 4 families lived in joint family structure and half of the study population was staying in kaccha-pakka (semimodern structure) types of houses (Table1).

Profile of Under-Five Children: Our finding shows that male children under three years of age were more prone to unintentional injury. Fall injury and burn injury was a most common unintentional injury. Majority of the injury was reported to be in the upper extremities $(31.39 \%)$ and followed by the head, lower extremities and face $(30.23 \%, 18.60 \%, 11.62 \%)$ respectively. Of total $(31.39 \%)$ injury occurred inside the home (i.e indoor environment) and followed by outside of the home, kitchen, and yard (29.06\%, 22.09\%, and $17.44 \%)$ respectively. The study also revealed that injury occurrence was prominent during the daytime. Notably, the majority of injury was severe, followed by mild and moderate $(39.53 \%, 37.20 \%$, and $23.25 \%)$ respectively. Commonly injury occurred due to the absence of the caretaker in the home while children are alone (Table.2).

Factors associated with unintentional injuries among the under-five children: Ecological belt, age of mothers, education of mothers, education of fathers, occupation of mothers, occupation of fathers, family income quintiles, types of household, number of siblings, age of children and gender of children showed significant association with unintentional injuries among under-five children (Table 3)

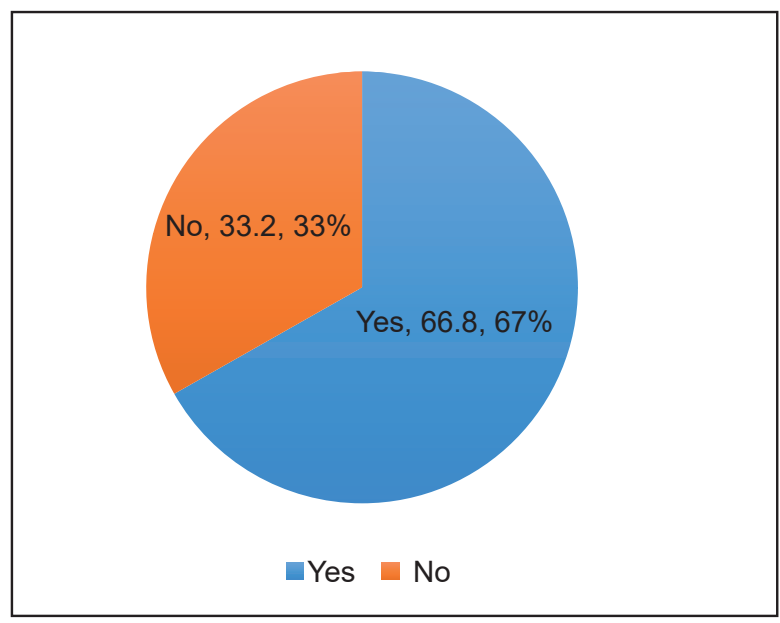

Fig 2: Prevalence of unintentional injuries among underfive children $(n=259)$

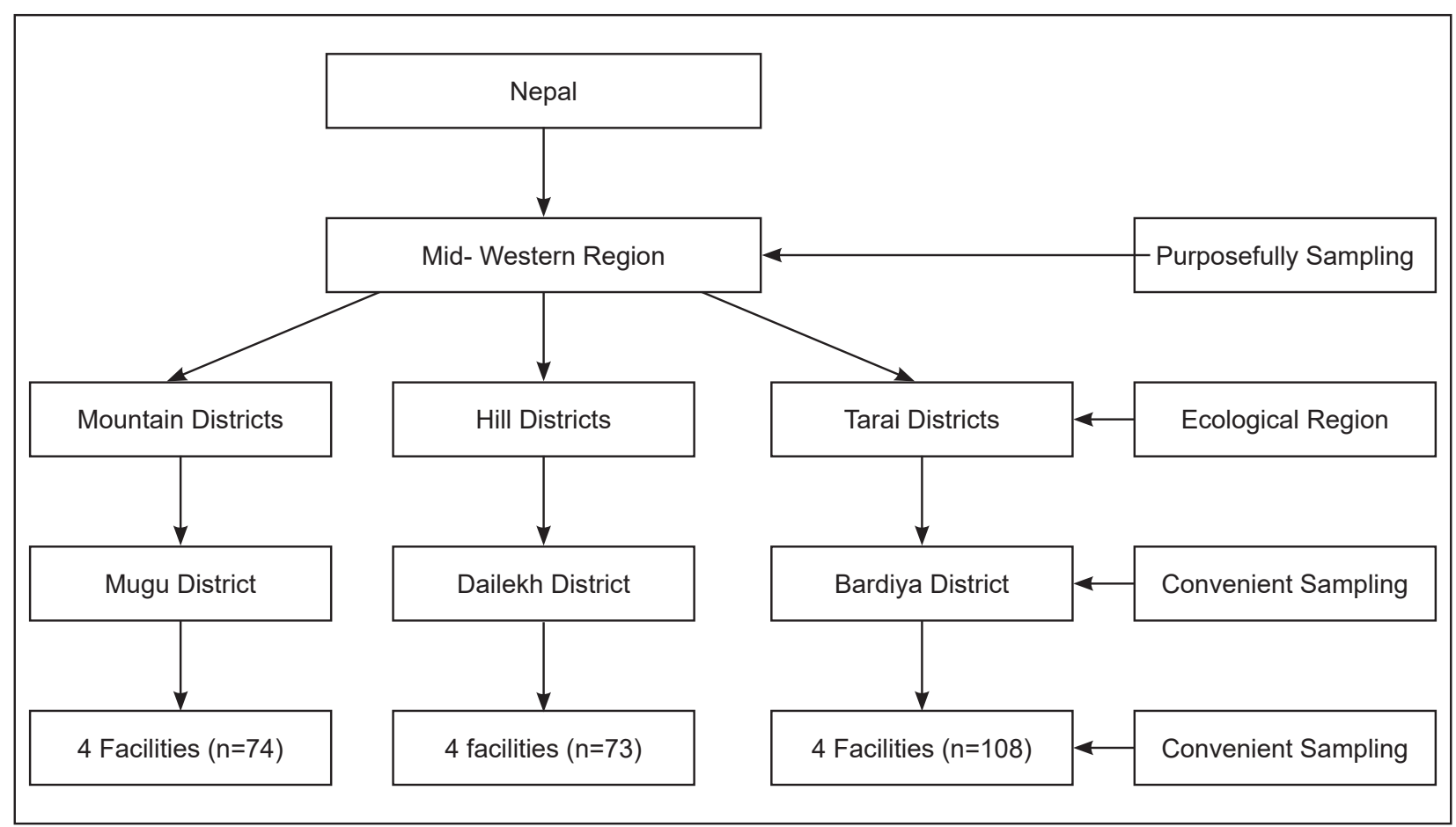

Fig. 1: Sampling model of multistage time frame located convenient sampling 
Table 1: Demographic Characteristics of the Respondent

\begin{tabular}{lcc}
\hline Category & Frequency (n) & Percentage (\%) \\
\hline Marital status & 259 & 100.0 \\
\hline Married & & \\
\hline Occupation status & 93 & 35.9 \\
\hline Agriculture & 14 & 5.4 \\
\hline Daily Wages & 32 & 12.4 \\
\hline Business & 101 & 39.0 \\
\hline Housewife & 8 & 3.1 \\
\hline Government Job & 11 & 4.2 \\
\hline Others & 65 & \\
\hline Education status of mothers & 25.1 \\
\hline No schooling & 56 & 21.6 \\
\hline Primary & 39 & 15.1 \\
\hline lower secondary & 42 & 16.2 \\
\hline secondary & 57 & 22.0 \\
\hline higher secondary & & \\
\hline Religious status & 243 & 93.8 \\
\hline Hindu & 10 & 3.9 \\
\hline Islam & 6 & 2.3 \\
\hline Others & & \\
\hline Occupation status of the & & \\
\hline
\end{tabular}

\section{Occupation status of the husband}

\begin{tabular}{lcc}
\hline Agriculture & 75 & 29.0 \\
\hline Daily Wages & 21 & 8.1 \\
\hline Business & 38 & 14.7 \\
\hline Government Job & 35 & 13.5 \\
\hline $\begin{array}{l}\text { Foreign } \\
\text { employment }\end{array}$ & 50 & 19.3 \\
\hline Others & 40 & 15.4
\end{tabular}

\section{Education status of Husband}

\begin{tabular}{lcc}
\hline No schooling & 34 & 13.1 \\
\hline Primary & 42 & 16.2 \\
\hline Lower Secondary & 42 & 16.2 \\
\hline Secondary & 62 & 23.9 \\
\hline Higher Secondary & 79 & 30.5 \\
\hline Type of family & & \\
\hline Nuclear & 57 & 22.0 \\
\hline Joint & 200 & 77.2 \\
\hline Others & 2 & .8 \\
\hline Types of house & & \\
\hline Kachha & 79 & 30.5 \\
\hline Pakka & 39 & 15.1 \\
\hline Kachha-Pakka & 141 & 54.4 \\
\hline Quintiles distribution & & \\
\hline Lowest & 73 & 28.2 \\
\hline Second & 33 & 12.7 \\
\hline Middle & 50 & 19.3 \\
\hline Fourth & 70 & 27.0 \\
\hline Richest & 33 & 12.7 \\
\hline Types of yard & & \\
\hline Plastered & 29 & 11.2 \\
\hline Unplastered & 230 & 88.8 \\
\hline & & \\
\hline
\end{tabular}

Table 2: Profile of children under five year's (U5) age

\begin{tabular}{|c|c|c|}
\hline Category & Frequency (n) & Percentage (\%) \\
\hline \multicolumn{3}{|c|}{ No. of U5 children in a home } \\
\hline 1 & 106 & 40.9 \\
\hline 2 & 133 & 51.4 \\
\hline 3 & 16 & 6.2 \\
\hline 4 & 4 & 1.5 \\
\hline \multicolumn{3}{|l|}{ Gender } \\
\hline Male & 142 & 54.8 \\
\hline Female & 117 & 45.2 \\
\hline \multicolumn{3}{|l|}{ Age } \\
\hline$<3$ & 183 & 70.7 \\
\hline$>3$-less or equal to 5 & 76 & 29.3 \\
\hline \multicolumn{3}{|l|}{ Types of injury } \\
\hline RTA & 1 & 1.16 \\
\hline Falls injury & 38 & 44.18 \\
\hline Burn & 26 & 30.23 \\
\hline $\begin{array}{l}\text { Sharp Instrument } \\
\text { Injury }\end{array}$ & 14 & 16.27 \\
\hline Animal bites & 7 & 8.13 \\
\hline \multicolumn{3}{|l|}{ Part of injury } \\
\hline Head & 26 & 30.23 \\
\hline Face & 10 & 11.62 \\
\hline Upper extremities & 27 & 31.39 \\
\hline Lower extremities & 16 & 18.60 \\
\hline Others & 7 & 8.13 \\
\hline \multicolumn{3}{|l|}{ Severity of the injury } \\
\hline Mild & 32 & 37.20 \\
\hline Moderate & 20 & 23.25 \\
\hline Severe & 34 & 39.53 \\
\hline \multicolumn{3}{|l|}{ Place of injury } \\
\hline Yard & 15 & 17.44 \\
\hline Outside of home & 25 & 29.06 \\
\hline Inside of home & 27 & 31.39 \\
\hline Kitchen & 19 & 22.09 \\
\hline \multicolumn{3}{|l|}{ Time of injury } \\
\hline Morning & 26 & 30.23 \\
\hline Day & 32 & 37.20 \\
\hline Evening & 26 & 30.23 \\
\hline Night & 2 & 2.32 \\
\hline \multicolumn{3}{|c|}{ Any kind of disability } \\
\hline Yes & 4 & 4.65 \\
\hline No & 82 & 95.35 \\
\hline Present & 39 & 45.35 \\
\hline Not present & 47 & 54.65 \\
\hline \multicolumn{3}{|c|}{ Situation during getting injury } \\
\hline Single & 37 & 43.02 \\
\hline With a friend & 14 & 16.27 \\
\hline Parents/Caretaker & 35 & 40.69 \\
\hline \multicolumn{3}{|c|}{ The responsibility of getting an injury } \\
\hline Children own self & 30 & 34.88 \\
\hline Parents & 39 & 45.35 \\
\hline Caretakers & 17 & 19.76 \\
\hline
\end{tabular}


Table 3: Association between socio-demographic characteristics and injury status

\begin{tabular}{|c|c|c|c|c|c|}
\hline \multirow{3}{*}{ Variables } & \multirow{3}{*}{ Category } & \multicolumn{2}{|c|}{ Recent Injury } & \multirow{3}{*}{$\begin{array}{c}\text { Frequencyl } \\
\text { Percentage }(\mathrm{N}=259) \\
\mathrm{N}(\%)\end{array}$} & \multirow{3}{*}{$p$-value } \\
\hline & & Yes $(n=86)$ & No $(n=173)$ & & \\
\hline & & $\mathbf{N}(\%)$ & N (\%) & & \\
\hline \multirow{3}{*}{ Ecological Belt } & Mountain & $34(39.5)$ & $44(25.4)$ & $78(30.12)$ & \multirow{3}{*}{$<0.001^{*}$} \\
\hline & Hill & $28(32.6)$ & $45(26.0)$ & $73(28.19)$ & \\
\hline & Tarai & $24(27.9)$ & $84(48.6)$ & $108(41.69)$ & \\
\hline \multirow{4}{*}{ Age of Mothers } & $<20$ & $8(9.30)$ & $21(12.14)$ & $29(11.19)$ & \multirow{4}{*}{$0.041^{*}$} \\
\hline & $21-25$ & $38(44.19)$ & $80(46.24)$ & $118(45.6)$ & \\
\hline & $26-30$ & $25(29.07)$ & $45(52.33)$ & $70(27.03)$ & \\
\hline & $>31$ & $15(17.440$ & $27(15.61)$ & $42(16.22)$ & \\
\hline \multirow{4}{*}{ Education of Mothers } & Illiterate & $23(26.74)$ & $42(24.28)$ & $65(25.09)$ & \multirow{4}{*}{$0.014^{*}$} \\
\hline & Primary & $25(29.07)$ & $31(36.05)$ & $56(21.62)$ & \\
\hline & High School & $23(26.74)$ & $58(33.53)$ & $81(31.27)$ & \\
\hline & College/Above & $15(17.44)$ & $42(24.28)$ & $57(22.01)$ & \\
\hline \multirow{4}{*}{ Education of Father } & Illiterate & $8(9.30)$ & $26(15.03)$ & $34(13.13)$ & \multirow{4}{*}{$0.039 *$} \\
\hline & Primary & $21(24.42)$ & $21(12.14)$ & $42(16.22)$ & \\
\hline & High School & $36(41.86)$ & $68(39.31)$ & $104(40.15)$ & \\
\hline & College/Above & $21(24.42)$ & $58(33.53)$ & $79(30.50)$ & \\
\hline \multirow{2}{*}{ Occupation of Mother } & Working & $62(72.09)$ & $85(49.13)$ & $147(56.76)$ & \multirow{2}{*}{$0.000^{*}$} \\
\hline & Not Working & $24(27.91)$ & $88(50.87)$ & $112(43.24)$ & \\
\hline \multirow{6}{*}{ Occupation of Father } & Agriculture & $29(33.72)$ & $46(26.59)$ & $75(28.96)$ & \multirow{6}{*}{$0.006^{*}$} \\
\hline & Daily Wages & $10(11.63)$ & $11(6.36)$ & $21(8.11)$ & \\
\hline & Business & $12(13.95)$ & $26(15.03)$ & $38(14.67)$ & \\
\hline & Government Job & $10(11.63)$ & $25(14.45)$ & $35(13.51)$ & \\
\hline & Foreign employment & $14(16.28)$ & $36(20.81)$ & $50(19.31)$ & \\
\hline & Others & $11(12.79)$ & $29(16.76)$ & $40(15.44)$ & \\
\hline \multirow{5}{*}{ Family Income Quintile } & Lowest & $26(30.23)$ & $47(27.17)$ & $73(28.19)$ & \multirow{5}{*}{$0.036^{*}$} \\
\hline & Second & $8(9.30)$ & $25(14.45)$ & $33(12.74)$ & \\
\hline & Middle & $17(19.77)$ & $33(19.08)$ & $50(19.31)$ & \\
\hline & Fourth & $22(25.58)$ & $48(27.75)$ & $70(27.02)$ & \\
\hline & Richest & $13(15.12)$ & $20(11.56)$ & $33(12.74)$ & \\
\hline \multirow{3}{*}{ Number of Siblings } & No & $27(31.40)$ & $79(45.66)$ & $106(40.93)$ & \multirow{3}{*}{$0.004^{*}$} \\
\hline & One & $49(56.98)$ & $84(48.55)$ & $133(51.35)$ & \\
\hline & Two Plus & $10(11.63)$ & $10(5.78)$ & $20(7.72)$ & \\
\hline \multirow{3}{*}{ Types of Household } & Kachha & $23(26.74)$ & $56(32.37)$ & $79(30.50)$ & \multirow{3}{*}{$0.011^{*}$} \\
\hline & Pakka & $7(8.14)$ & $32(18.50)$ & $39(15.06)$ & \\
\hline & Kachha-Pakka & $56(65.1)$ & $85(49.1)$ & $141(54.44)$ & \\
\hline \multirow{2}{*}{ Age of the Children } & $<3$ & $49(56.98)$ & $134(77.46)$ & $183(70.66)$ & \multirow{2}{*}{$0.000^{*}$} \\
\hline & $>3$ - less or equal to 5 & $37(43.02)$ & $39(22.54)$ & $76(29.34)$ & \\
\hline \multirow{2}{*}{ Gender } & Male & $53(61.63)$ & $89(51.45)$ & $142(54.83)$ & \\
\hline & Female & $33(38.37)$ & $84(48.55)$ & $117(45.17)$ & $0.032^{n}$ \\
\hline
\end{tabular}

Note: $p$-value $<0.05$ shows the significance association and* indicates statistical significance

\section{Discussion}

There was dearth of studies on unintentional injuries among under-five children in mid-western Nepal and this study came out with some interesting findings. Our finding shows that the prevalence of unintentional injury was $33.20 \%$. This is supported by the study conducted by Eldosoky et al. in Egypt, where author showed slightly high prevalence as compared to our result that is $38.3 \%^{12}$. Similarly, another study conducted in India by Shriyan et al. showed a prevalence of $46.3 \%$ which is comparatively higher than our study ${ }^{6}$. Our findings indicate that male children under-three years of 
age were at high risk of unintentional injury. This finding is unison with the findings of previous other author studies $^{11,12}$. In contrast, a study done in Iran and India found injuries were common among children above three years of age $\mathrm{e}^{6,11}$.

In the study fall injury, burning and sharp instrument injuries were the most common types of injury. Similar findings were observed in previous other author studies. Children living in mountain ecological belt were more at risk for injury, which might be because of the topography of land and lifestyle of peoples in the mountain, education status, and age of mothers were notable factors that make children more prone to injury. It could be explained in a way that uneducated mothers and those of early age have very less information and knowledge regarding rearing and caring of a child and the preventive methods to avoid unintentional injury among children's. Similarly, the results from Iran and India evidenced that mother's education and age of mothers is a risk factor for unintentional injuries of children ${ }^{6,11}$.

We found mothers in working status by occupation and having only one child were associated with the occurrence of unintentional injuries among children. The possible reason could be mostly women are involved in the agro-based economy and have less time to take care of the siblings during the work period, and they often leave they're children at home for better work outputs. In this light the results from previous other author studies also evidenced it $^{9}$. In addition, education and occupation of the father were found to be associated with the occurrence of unintentional injuries among under-five children. This might be because the illiterate parent and basically farmer parent have less time and knowledge to care and rearing children. Consistent results are shown by a study from different setting ${ }^{6,12,24}$. In this study, we found lower socio-economic (lowest and fourth quintile),

\section{References}

1. Peden M, Oyegbite K, Ozanne-Smith J, Hyder AA, Branche C, Rahman FA. et al. World report on child injury prevention. Switzerland: World Health Organization. Report no.232, 2008.

2. NSW Child Death Review Team CHSD, AHSRI and W.U. A scan of childhood injury and disease prevention infrastructure in NSW. Australia: NSW Ombudsman. Report no.64, 2015.

3. Hyder AA, Sugerman ED, Puvanachandra P, Razzak $J$, EL-Sayed H, Isaza A. et al. Global childhood unintentional injury surveillance in four cities in developing countries: a pilot study. Bull World Health Org 2009;87:345-52. DOI: 10.2471/BLT.08.055798 living standard, low quality of housing (Kachha-Pakka) and worked father are risk factors for injury. This might be due to low economic status or poverty push children in vulnerability to injury. The lower socio-economic status household had less chance to build up the quality living standard and quality house, this lead to fathers spend more time working and less time to rear and care of children. Similarly, other study conducted in Iran, India, Australia, Peru, and China $6,11,13,14,24$.

As like other studies, this study does have some strengths and limitations of its own. This study provides the picture of unintentional injuries among under-five children of selected districts of the Mid-western region comprising the all three ecological regions of Nepal. This study hopes to influence the larger studies to capture this issue so that child injury interventions can be designed. Despite the strengths, our limitation is that we adopted time-frame convenient sampling and the tool was semi-structured based on literature review, so it's genuine to have questions on the generalizability of the findings to the whole development regions. Furthermore, the information was collected from mothers of underfive children, where recall bias could not be ignored, however, the research team tried to minimize it using one interviewer during the entire data collection process.

\section{Conclusion}

The prevalence of unintentional injuries in children from western Nepal were significant and based upon the results we suggest the need of intervention addressing multi-factorial factors focusing on social determinants of health like economy and jobs, ways to increase household income, focus on education, modify the social and physical environment of home and the community. Further, this study insists on the need to conduct the study at a large scale to capture the problems in a more systematic and scientific way.

4. Bhatta S. Community-based home injury risk assessment in rural Nepal [PhD thesis]. University of the west of England 2017. Available from: http:// eprints.uwe.ac.uk/32549/

5. Jagnoor J, Bassani DG, Keay L, Ivers RQ, Thakur JS, Gururaj $\mathrm{G}$ et al. Unintentional injury deaths among children younger than 5 years of age in India: a nationally representative study. Inj Prev 2011;17(3);151-55. DOI: 10.1136/ip.2010.029934. Epub 2011 Apr 14

6. Shriyan P, Prabhu V, Aithal KS, Yadav UN, Orgochukwu MJ. Profile of unintentional injuries under-five children in coastal Karnataka, India: a cross-sectional study. Int J Med Sci Pub Health 2014;3:1317-319. DOI: 10.5455/ ijmsph.2014.020820141 
7. Pant RP, Towner E, Ellis M, Manandhar D, Pilkington P, Mytton J. Epidemiology of unintentional child injuries in the Makwanpur district of Nepal: a household survey. Int J Environ Res Pub Health 2015;12:15118-28. DOI: 10.3390/ijerph121214967

8. Chandran A, Khan RU, Zia N, Feroze A, Ramirez SS, Huang C. et al. Disseminating Childhood Home injury Risk Reduction Information in Pakistan. Int J Enviran Res Pub Health 2013;10:1113-24. DOI: https://doi. org/10.3390/ijerph10031113

9. Bartlett NS. The problem of children's injuries in lowincome countries: a review. Health Policy and Planning Oxford University Press; 17(1) 1-13.

10. Sleet AD, Gielen CA. Population health: Behavioral and social science insights (application of behavior change theory to preventing unintentional injuries). Agency for healthcare research and quality 2015 Available at: https://www.ahrq.gov/professionals/education/ curriculum-tools/population-health/sleet.html

11. World Health Organization. The Global burden of disease. Switzerland, WHO press 2004.

12. Birgul P, Ocaktan ME, Akdur R, Soner YM, Sevil I, Safa C. Evaluation of unintentional injuries sustained by children: A hospital based study from Ankara-Turkey. Pak J Med Sci 2013:29(3):832-36. DOI: http://dx.doi. org/10.12669/pjms.293.3150.

13. Poulos R, Hayen A, Finch FC, Zwi A. Area socioeconomic status and childhood injury morbidity in New Soth Wales, Australia. Inj Prev 2007;13(5):32227. DOI: 10.1136/ip.2007.015693.

14. Delgado J, Ramirez-Cardich M E, Gilman R H, Lavarello R, Dahodwala N, Bazan A et al. Risk Factors for burns in children: crowding, poverty, and poor maternal education Inj Prev 2002;8;38-41. DOI: http:// dx.doi.org/10.1136/ip.8.1.38

15. Forijuohn NS, Guye B, Strobino D, Keyl MP, West DM, Smith SG et al. Risk factors for childhood burns: a case-control study of Ghanaian children. J Epidemiol Comm Health 1995,49:189-193. DOI: http://dx.doi. org/10.1136/jech.49.2.189.
16. Werneck GL, Reichenheim ME. Paediatric burns and associated risk factors in Rio de Janeiro, Brazil. Burns 1997;23(6):478-83. DOI: https://doi.org/10.1016/ S0305-4179(97)00046-6

17. Khambalia A, Joshi P, Brussoni M, Macarthur C. Risk factors for unintentional injuries due to falls in aged 0-6 years: A systematic review. Inj Prev 2006;12:378-85. DOI: http://dx.doi.org/10.1136/ip.2006.012161

18. Jagnoor J, Suraweera W, Keay L, Ivers QR, Thakur JS, Gururaj $G$ et al. Childhood and adult mortality from unintentional falls in India. Bull WHO 2011;89:733-740. DOI: 10.2471/BLT.11.086306.

19. AAP Committee on injury and poison prevention pediatrics. Falls from heights: windows, roofs and Balconies. Pediatrics 2001;107(5);1188. DOI: 10.1542/ peds.107.5.1188

20. Towner E. The prevention of childhood unintentional injury. Paediatr Child Health 2001;11(6):403-408. DOI: http://dx.doi.org/10.1054/cupe.2001.0227

21. Towner E, Ward H. Prevention of injuries to children and young people: the way ahead for the UK. Inj Prev 2017;4:S17-S25. DOI: http://dx.doi.org/10.1136/ ip.4.2008.S17.

22. Mackay M,Vincenten J, Brussoni M, Towner L Child safety good practice guide: good investments in unintentional child injury prevention and safety promotion. Amsterdam: European Child Safety Alliance, (Eurosafe);2006.

23. Sleet AD, Gielen CA. Population health: Behavioral and social science insights (application of behavior change theory to preventing unintentional injuries). Agency for healthcare research and quality $2015 \mathrm{https}: / / \mathrm{www}$. ahrq.gov/professionals/education/curriculum-tools/ population-health/sleet.html.

24. Qin X, Wacharasin C, Deoisres W, Yu J, Zheng Q. Characteristics and predictors of home injury hazards among toddlers in Wenzhou, China: a community based cross-sectional study. BMJ Pub Health 2014;14:638. DOI: https://doi.org/10.1186/1471-2458$14-638$. 